\title{
Study of moisture transfer through unsaturated zone and groundwater recharge at the emergency site of the Solikamsk-2 Mine (Verkhnekamskoye salt deposit, Russia)
}

\author{
Konstantin Vladimirov $^{1 *}$, Anton Nikulenkov ${ }^{1,2}$, and Aleksey Shvartc ${ }^{1,2}$ \\ ${ }^{1}$ Saint Petersburg Division of the E.M. Sergeev Institute of Environmental Geology of the Russian \\ Academy of Sciences, Sredniy Ave, 41, 190004, St. Petersburg, Russia \\ ${ }^{2}$ Saint Petersburg State University, 7/9 Universitetskaya Emb, 199034, St. Petersburg, Russia
}

\begin{abstract}
The article provides the results of assessing groundwater recharge at the emergency site of the Solikamsk-2 Mine (Solikamsk, Russia). The assessment was performed using two separate approaches, including the study of the results of groundwater level observations and numerical modeling of soil moisture transfer through the unsaturated zone. The analysis of the groundwater level fluctuations in observation wells made it possible to estimate the recharge rate in natural and anthropogenic (after the accident) conditions. To study the soil moisture transfer in the upper part of the unsaturated zone two moisture sensors were installed at a depth of 0.4 and $0.65 \mathrm{~m}$. To interpret sensors data the numerical model was developed using the HYDRUS 1D software. The modeling results allowed estimating the recharge rate at a depth of $0.65 \mathrm{~m}$ and the main water balance components (evaporation, transpiration, surface runoff). A comparison of the two methods showed similar results, allowing them to use for estimating and predicting groundwater recharge in the annual cycle.
\end{abstract}

\section{Introduction}

On 5 January 1995, an emergency occurred at the Solikamsk-2 Mine (Solikamsk, Russia) inside the Verkhnekamskoye salt deposit due to the destruction of mine pillars on the area $950 \times 750 \mathrm{~m}$. As a result, a subsidence trough formed on the surface with a depth of more than $4 \mathrm{~m}$, and in November 2014, a sinkhole with a depth of $80 \mathrm{~m}$ was formed (Fig.1). The emergence of the sinkhole led to the groundwater penetration from the above-salt aquifers into the mine, creating a real danger of the mine flooding. The construction of a circular contour of vertical dewatering wells, equipped on the upper aquifer and located $300 \mathrm{~m}$ from the sides of the sinkhole, was the main method for limiting water inflow into the mine. To date, the dewatering contour includes more than 60 wells and its average annual discharge (for 2019) is about $5000 \mathrm{~m}^{3} / \mathrm{h}$. Due to these efforts, water inflows into the mine have been stabilized at $100-300 \mathrm{~m}^{3} / \mathrm{h}$.

*Corresponding author: vladimirov@hgepro.ru 


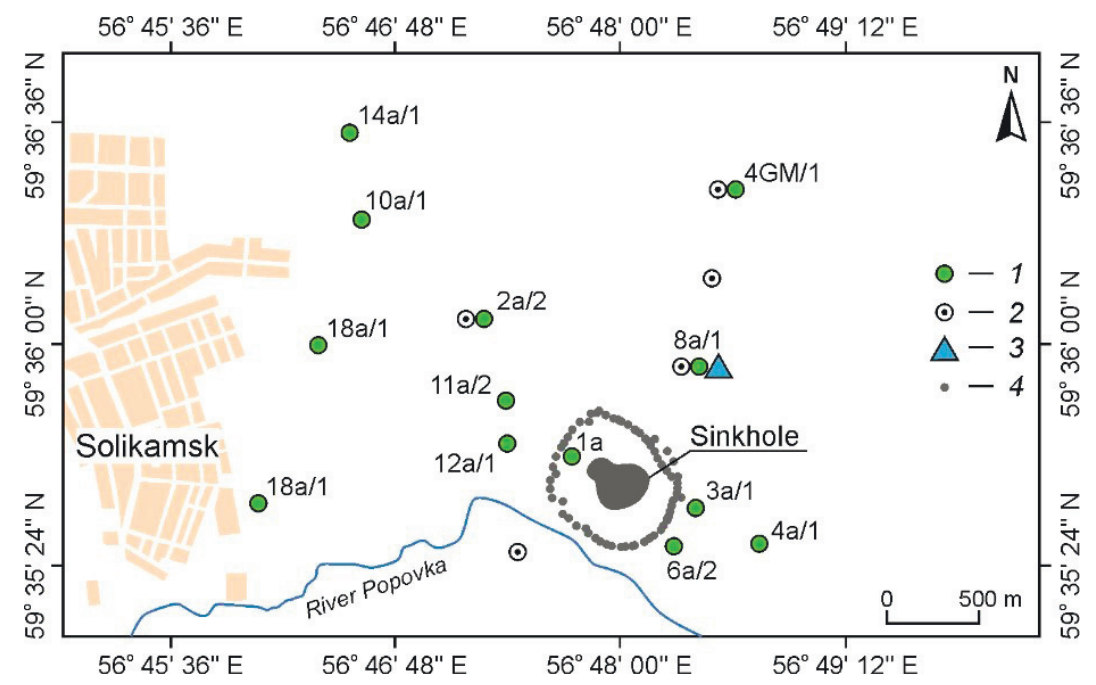

Fig. 1. Study area. 1 - observation well (groundwater); 2 - engineering geological borehole for soil sampling; 3 - soil moisture sensors location; 4 - dewatering wells.

The consequences of the emergency affected the geological and hydrogeological conditions of the study area. The groundwater discharge into the sinkhole area (into the mine), as well as construction of dewatering wells, resulted in a groundwater level drawdown by more than $30 \mathrm{~m}$ and a rise of unsaturated zone thickness to $90-120 \mathrm{~m}$. The rock fracturing near the sinkhole significantly increased and, as a result, its permeability increased. Finally, the natural water balance of the study area was changed, mainly due to a decrease in the discharge of groundwater flow into the streamflow.

Further situation at the emergency site largely depends on the ability to predict water inflows into the mine. The aim of this article is to approve efficient and cost-effective methods for assessing and predicting groundwater recharge as one of the main causes of groundwater level fluctuations and seasonal changes in water inflows into the mine. The widely used methods for assessing the groundwater recharge based on streamflow level and discharge measurements and the hydrograph separation are not considered in this article due to the anthropogenic regime of the closest surface drain (the Popovka River). Alternative approaches, therefore, were used based on groundwater levels observations and soil moisture measurements in the unsaturated zone. Due to the significant thickness of the unsaturated zone (up to $90-120 \mathrm{~m}$ ), some time lag from the moment of precipitation to the surface until it reaches the groundwater level can be expected. The presence of a time lag makes it possible to predict fluctuations in groundwater levels.

\section{Methods}

\subsection{Recharge rate estimation based on groundwater level fluctuations}

Recharge rate can be calculated on the basis of groundwater levels observations [1]. This approach is based on the relationship between changes in groundwater level amplitude and the recharge rate:

$$
R\left(t_{j}\right)=S_{y} \Delta H\left(t_{j}\right)
$$


where $R\left(t_{j}\right)$ is the aquifer recharge for one event (e.g., snowmelt, rain), m; $S_{y}$ is the specific yield of the aquifer; $\Delta H\left(t_{j}\right)$ is the amplitude of groundwater level fluctuations over the period of one event, $\mathrm{m}$.

The annual recharge rate is the sum of $R\left(t_{j}\right)$ for each event. The amplitude $\Delta H\left(t_{j}\right)$ is defined as the difference between the maximum level for one event and the value extrapolated from the recession curve until the maximum of the next event occurs. The $S_{y}$ value for the study area was derived based on the results of the development and calibration of the numerical groundwater flow 3D-model and assumed to be 0.04 [2].

The groundwater recharge was estimated using available data from observation well No. 1a from 1999 to 2011 and under natural conditions. After the sinkhole, the calculation was made for 12 more wells assuming that during the calculation period from January to June 2019, the dewatering wells operated with constant discharge, and the depression cone in groundwater had already reached the general drain (Kama River) and stabilized.

\subsection{Soil moisture content observations}

The assessment of potential recharge rate is possible due to regular observations of the soil moisture profile of the unsaturated zone $[3,4]$. For this purpose, two soil moisture sensors were installed near the $8 \mathrm{a} / 1$ observation well. The first sensor was installed vertically at the bottom of a well drilled to a depth of $0.65 \mathrm{~m}$, followed by backfilling and tamping with uncovered soil. The second sensor was installed horizontally in a pit to a depth of $0.4 \mathrm{~m}$ and followed by recovery of natural landscape. Both sensors were connected to a data logger with the ability to transmit data via a GPRS-modem. Volumetric soil moisture data were recorded 1 time every 4 hours.

\subsection{Soil sampling}

In October and November 2018, five engineering-geological wells were drilled to study the grain-size composition and physical properties of soil samples in the unsaturated zone. The drilling was conducted using the URB-2A2 drilling rig to a depth of $70 \mathrm{~m}$ and the drilling method was dry core with casing of upper part with unstable soils. 33 samples of the Quaternary rock (silty clay, loam) and 52 samples of bedrock (marl, limestone, mudstone) were collected. Two samples were also collected at the soil moisture sensor location. The Quaternary rock samples were collected using a hammer sampler, bedrock - using a core pipe.

\subsection{Numerical modeling of soil moisture transfer through the unsaturated zone}

The interpretation of soil moisture observations, the calculation of the potential recharge, and the assessment of the main components of the water balance were conducted using numerical methods. The HYDRUS-1D version 4.17 [5] software package was used to create a numerical model. It allows simulating one-dimensional soil moisture transfer in the unsaturated zone taking into account evapotranspiration, snow accumulation, snowmelt and surface runoff.

The vertical size of the model was $0.65 \mathrm{~m}$, corresponding to the maximum depth of the soil moisture sensor. At the upper boundary of the model, atmospheric conditions were set: air temperature, precipitation, and evapotranspiration. The lower boundary was set as a free drainage.

The calculation was made using the indirect Penman-Monteith method [6] to estimate the total evapotranspiration. The method is based on the determination of the reference 
evapotranspiration using standard daily resolution climate data. The climate data were collected at the Berezniki meteorological station for the period October 30, 2018 October 29, 2019 [7]. The data included air temperature at a height of $2 \mathrm{~m}$, precipitation, wind speed at a height of $10 \mathrm{~m}$, relative air humidity. Solar radiation data for the study area were taken from open sources [8]. The average daily values of the parameters were used for model calculations, except precipitation, which was taken from the daily sum.

Soil moisture simulation based on the Van Genuchten-Mualem equation [9]. The water retention properties of the soil were calculated using the Rosetta Lite module [10]. The input data for the calculation were the average bulk density and the grain-size composition of the Quaternary sediments. The results of the calculation of water retention properties are provided in Table.

The model was calibrated by changing the input parameters so that the simulated and observed soil moisture showed the best match. The main parameter for model calibration was the evapotranspiration value.

Table. Water retention properties of the simulated soils.

\begin{tabular}{|c|c|c|c|}
\hline Parameters in Van-Genuchten equation & Notation & Dimension & Value \\
\hline Saturated hydraulic conductivity & $K_{S}$ & $\mathrm{~m} / \mathrm{day}$ & 0.03 \\
\hline Residual soil water content & $\theta_{r}$ & $\%$ & 3 \\
\hline Saturated soil water content & $\theta_{S}$ & $\%$ & 26.7 \\
\hline Parameter in soil water retention function & $\alpha$ & $1 / \mathrm{m}$ & 2.89 \\
\hline Parameter in soil water retention function & $n$ & - & 1.24 \\
\hline Tortuosity & $I$ & - & 0.5 \\
\hline
\end{tabular}

\section{Results and discussions}

The results of calculations by groundwater level fluctuations show that the long-term annual recharge for well No. 1a in natural conditions is from 124 to $233 \mathrm{~mm}$, and for the spring flood season is $112-194 \mathrm{~mm}$. At the same time, more than $75 \%$ of snow storage is spent on groundwater recharge.

Groundwater observation data showed that under natural conditions, the peak of flood period in groundwater occurs 90 days ( \pm 10 days) after snow melt. It was found that there is a strong correlation between the maximum amplitude of groundwater levels and snow storage (Fig. 2a). Such an empirical relationship allows to confidently predicting the rise in water levels during flood periods, based only on data on snow storage from the meteorological observing station.

Due to spring snowmelt in 2019 (anthropogenic conditions after sinkhole), the recharge rate according to observations from 12 wells ranged from 130 to $230 \mathrm{~mm}$ (from 52 to $92 \%$ of snow storage). Sufficient spread in recharge rate is probably related to the variability of geological and hydrogeological conditions over the study area, and mainly to increased fracturing of the rocks near the sinkhole. This is indirectly confirmed by the fact that, with the exception of two wells, there is a strong correlation between the recharge rate and the distance to the sinkhole (Fig. 2b).

As a result of the numerical model calibration, it was achieved a satisfactory agreement between simulated and observed soil moisture according to the data of two sensors at depths of 0.4 and $0.65 \mathrm{~m}$ (Fig. 3a). Both the simulated and observed graphs show periods of low water in winter and the beginning of the spring flood period. During the spring flood, three peaks of soil moisture are observed. The first two of them are controlled by the snowmelt rate, and the third peak characterizes intense rains in mid-May. Soil moisture changes in summer are largely controlled by transpiration and evaporation. At the beginning of August, a quick rise of moisture was caused by intensive rains. Excessive 
rainy August and October, when more than $300 \mathrm{~mm}$ of precipitation fell, formed the second flood period.
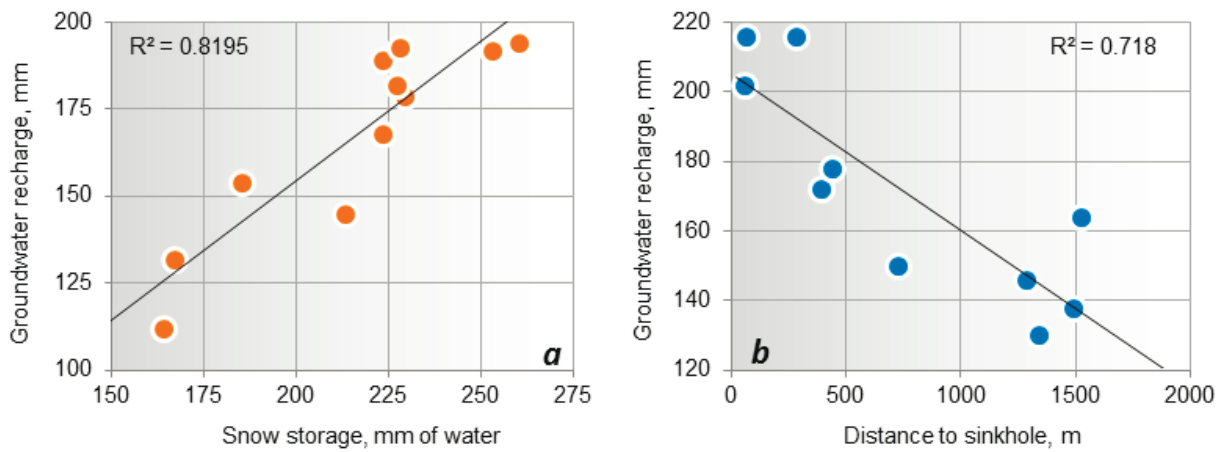

Fig. 2. Correlations between recharge rate and snow storage (a) and recharge rate and distance to sinkhole (b).

The simulation results made it possible to quantify main water balance components. For the annual period (October 30, 2018 - October 29, 2019), $827 \mathrm{~mm}$ of precipitations was recorded at the Berezniki meteorological station. This amount of water was set in the model on the upper boundary condition. $109 \mathrm{~mm}$ of water (13\% of precipitations) was spent on runoff. $535 \mathrm{~mm}$ of water was spent on infiltration. From this amount $307 \mathrm{~mm}(37 \%$ of precipitations) reached the free drainage boundary at a depth of $0.65 \mathrm{~m}$ and can be considered as the recharge rate. Part of the infiltrating water is spent on evaporation from the surface $(324 \mathrm{~mm})$ and transpiration to a depth of $0.4 \mathrm{~m}(74 \mathrm{~mm})$. The sum of all components of the simulated water balance is $814 \mathrm{~mm}$. In this case, the discrepancy of $13 \mathrm{~mm}(1.6 \%$ of precipitations) is caused by the fact that precipitations for last time steps did not reach the lower boundary.

The modeling results show the irregularity in the distribution of recharge rate over time. There are three periods of intense recharge on the diagram (Fig. 3b). The first of them is a consequence of the autumn flood in 2018 and is characterized by recharge rate up to 1$2 \mathrm{~mm} /$ day in the first two decades of November. The second period is associated with spring flood due to snowmelt in April and intensive rains in May 2019. During this period, the recharge rate reached its maximum for the entire simulated period - up to $12 \mathrm{~mm} /$ day on April 8-10. The third period begins with the third decade of August and continues throughout the autumn period due to the intensive rains in August and October.

Therefore, the present study provides two methods for calculating the groundwater recharge. The first method is based on groundwater level fluctuations in observation wells located in sinkhole area. The long-term annual recharge for well No. 1a in natural conditions is from 124 to $233 \mathrm{~mm}$, and for the flood season from 112 to $194 \mathrm{~mm}$. In 2019 , the recharge rate for 12 wells during the spring flood period ranged from 130 to $230 \mathrm{~mm}$. A significant correlation between the amount of snow storage and recharge allows predicting the groundwater recharge rate for 80-100 days after the positive average daily air temperatures in the first spring months. The second method for calculating recharge rate was developed by using a numerical model of soil moisture transfer through unsaturated zone. The model took into account the basic surface processes and estimating the recharge rate based on the water balance. The simulation results gave the recharge rate for a depth of $0.65 \mathrm{~m}$ near the observation well No. 8a. The simulation recharge rate for the annual cycle from October 30, 2019 to October 29, 2019 was 307, and for the spring flood period $143 \mathrm{~mm}$. Overall, both methods have rather close results and showing that precipitations reach groundwater over a period of 80-100 days. 


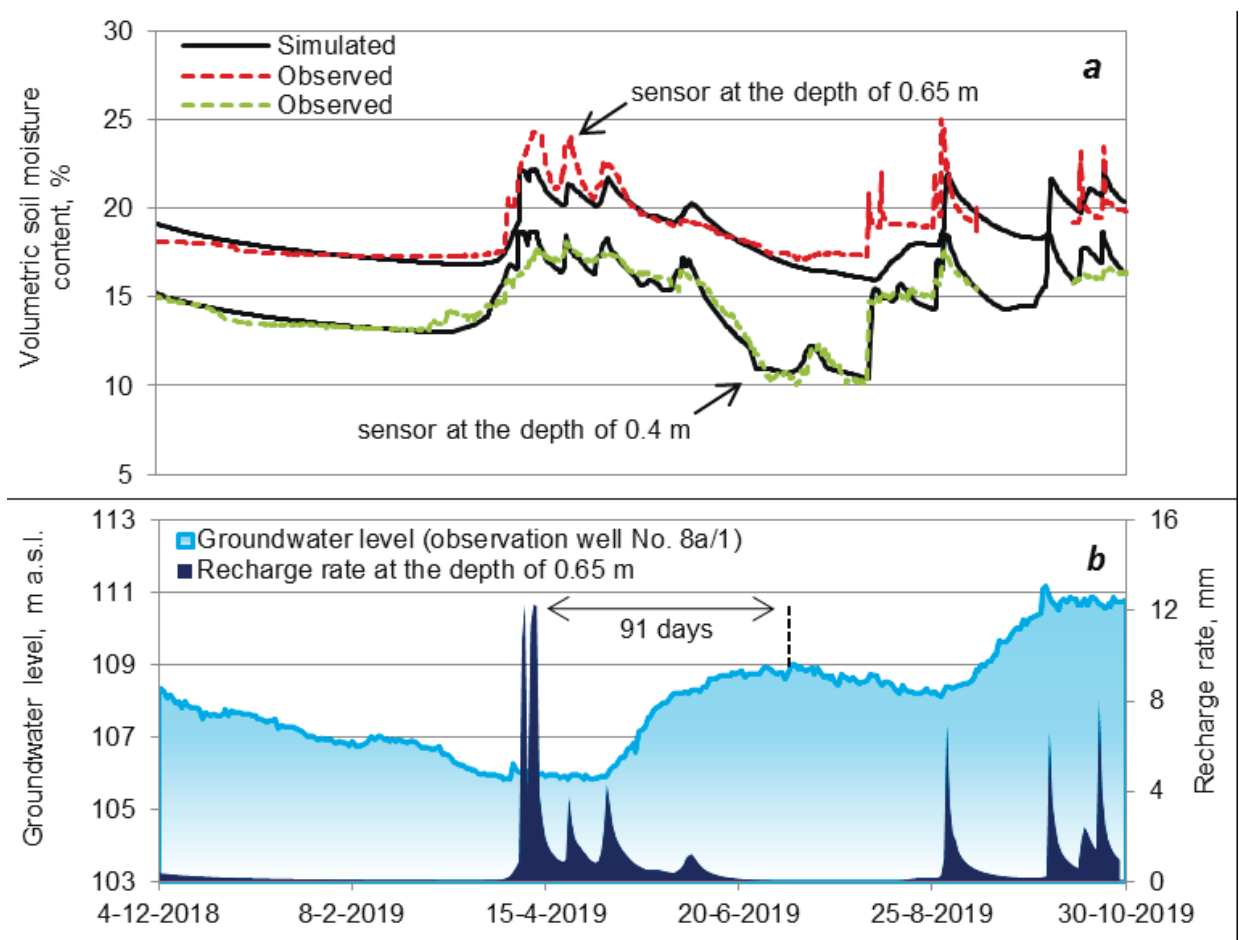

Fig. 3. Simulated and observed soil moisture at a depth of 0.65 and $0.4 \mathrm{~m}$ (a) and simulated distribution of recharge rate (b).

The authors are grateful to Leonid Lesnichiy (PJSC Uralkali) for field works organization support under Contracts No. 1331/2019/84 and 7237/2018/84.

\section{References}

1. O. Meinzer, The occurrence of groundwater in the United States with a discussion of principles (US Geol. Survey Water Supply Pap., Washington, 1923)

2. V. Rumynin, S. Makashov, Selection of the optimal site for the discharge of transit water in order to minimize the impact of the dewatering facilities of the SKRU-2 Mine on the groundwater (Technical Report IEG RAS, Saint Petersburg, 2018)

3. R. W. Healy, B. R. Scanlon, Estimating groundwater recharge (Cambridge University Press, New York, 2010)

4. G.D. Delin, R.W. Healy, M.K. Landon, J.K. Böhlke, J. of AWRA 36, 6 (2000)

5. J. Šimunek, M. Šejna, H. Sakai, M. Th. van Genuchten, The HYDRUS-1D Software Package for Simulating the One-Dimentional Movement of Water, Heat, and Multiple Solutes in Variably-Saturated Media. User manual - Version 4.17 (Department of Environmental Sciences, University of California Riverside, Riverside, CA, 2018)

6. R. G. Allen, L. Pereira, D. Raes, M. Smith, FAO Irrigation and drainage paper 56, 6566 (1998)

7. [URL]:https://rp5.ru/Погода в Березниках, Березники (Accessed 25.11.2019)

8. [URL]:https://power.larc.nasa.gov/data-access-viewer/ (Accessed 25.11. 2019)

9. M. Th. Van Genuchten, Soil Sci. Soc. Am. J., 44, $892-898$ (1980)

10. M. G. Schaap, F. J. Leij, M. Th. van Genuchten, J. of Hydrol., 251, 163-176 (2001) 